\title{
Entrevista a Carmina Narro
}

\section{Alfonso Varona}

Carmina Narro nació en 1969 en Los Mochis, en el estado mexicano de Sinaloa. A partir de los años noventa ha destacado como dramaturga, directora de escena de sus propias obras, cuentista y guionista para la televisión. Sus maestros fueron Héctor Mendoza y Raúl Quintanilla (actuación, en el Núcleo de Estudios Teatrales), Hugo Argüelles (dramaturgia), Vicente Leñero (análisis teatral) y Juan José Gurrola (dirección de escena).

Su primera obra, Recuerdos de bruces (1992), ganó el Premio Salvador Novo como Revelación en Dramaturgia por la Unión de Cronistas y Críticos Teatrales. Credencial de escritor (1996) obtuvo el Premio Bravo a la Mejor Comedia del Año por la Asociación Rafael Banquells. Posteriormente ha estrenado Ay, mi vida, qué tragedia, La luna en escorpión, Aplausos para Mariana (1997), Químicos para el amor (2002), Julio sin agosto (2006) y Cuestión de tres, premiada por la Agrupación de Críticos y Periodistas Teatrales (2013). ${ }^{1}$

En el 2002 fue beneficiaria del Programa de Intercambio de Residencias Artísticas México-Nueva York por parte del Fondo Nacional para la Cultura y las Artes (FONCA), The Writers Room de Nueva York y la Sociedad General de Escritores Mexicanos (SOGEM). En el año 2005 es invitada por la New School University de Nueva York para escribir y dirigir la ópera Loveless Scenes con música de Jorge Sosa. Como primera parte de dicho espectáculo dirige su obra Round de sombras con actores del Actors Studio y el Repertorio Español. Ha sido además becaria del taller de dramaturgia Royal Court Theatre de Londres.

En 1994 adaptó y dirigió Recordando con ira, de John Osborne, y en el 2002 dirigió Estrategias contra el miedo de Ricardo García. Asimismo adaptó El misántropo o el violento enamorado, de Molière, en cartelera del 23 de mayo al 3 de agosto del 2014 en el Teatro Helénico de la ciudad de México. 
Sus cuentos han aparecido en diversas publicaciones, incluyendo el Libro de Lectura Gratuito para $4^{\circ}, 5^{\circ}$ y $6^{\circ}$ de Educación Primaria de la Secretaría de Educación Pública (SEP) en el 2011. Entre sus guiones para televisión, destacan las telenovelas El amor de mi vida (Argos-Azteca, 1998), El alma herida (Argos-Telemundo, 2003), y El señor de los cielos, 2a temporada (Telemundo-Caracol-Argos, 2014).

La presente entrevista se realizó en el restaurante La Fonda Garufa, en la colonia Condesa de la ciudad de México, el 27 de junio del 2014.

\section{$1^{a}$ parte. Formación, obra dramatúrgica general, y dirección escénica}

Naciste en Los Mochis, Sinaloa, y a los tres años tu familia se mudó para el DF. ¿Guardas una relación con tu estado natal, ya sea personal o profesionalmente?

No; yo nací en Sinaloa porque allí trabajaba mi papá; él era de Coahuila, mi mamá es de Sonora. Diríamos que tengo la cultura norteña por todos lados.

¿A qué edad y/o cómo surgió tu interés por la literatura y el teatro?

Yo escribía desde chica, como desde los ocho: cuentos, poesía, pensamientos. De hecho, después me fui más hacia el cuento. En la secundaria, en la clase de español nos dejaron escribir una obra de teatro; fue terrible para mí porque no encontraba la manera. El maestro nos puso a todos a escribir, pero pocas lo llevamos a cabo. La obra que escribí la dirigí con mis compañeritas. Ese fue mi primer acercamiento a la escritura dramática.

¿Qué maestros/as consideras fundamentales en tu formación como dramaturga y directora? ¿Cuáles consideras tus influencias literarias?

En la secundaria se formó mucho de lo que soy ahora. Recuerdo haber leído La gaviota de Chéjov y El misántropo de Molière; ambas me impresionaron. La lectura de El misántropo fue definitiva porque me di cuenta que no estaba sola; había un Alceste ahí, adolescente eterno, y yo estaba en la adolescencia [risa]. También fue muy importante leer El extranjero de Camus, a los doce años. Me traumaticé bastante; pensé "este hombre no cree en Dios" y después me metieron en una escuela de monjas [risa].

Todos mis maestros fueron fundamentales, pero con el que tuve más cercanía fue con Juan José Gurrola. Lo asistí en dirección y siempre fui muy cercana a él. Por ejemplo, yo terminaba de escribir una obra y se la enseñaba. Siempre me decía "Dime la primera línea", y al escucharla él decidía si la leía o no. Me dio un punto muy importante; si la primera línea no provoca algo, lo que sea, hay que replantearse la obra. 


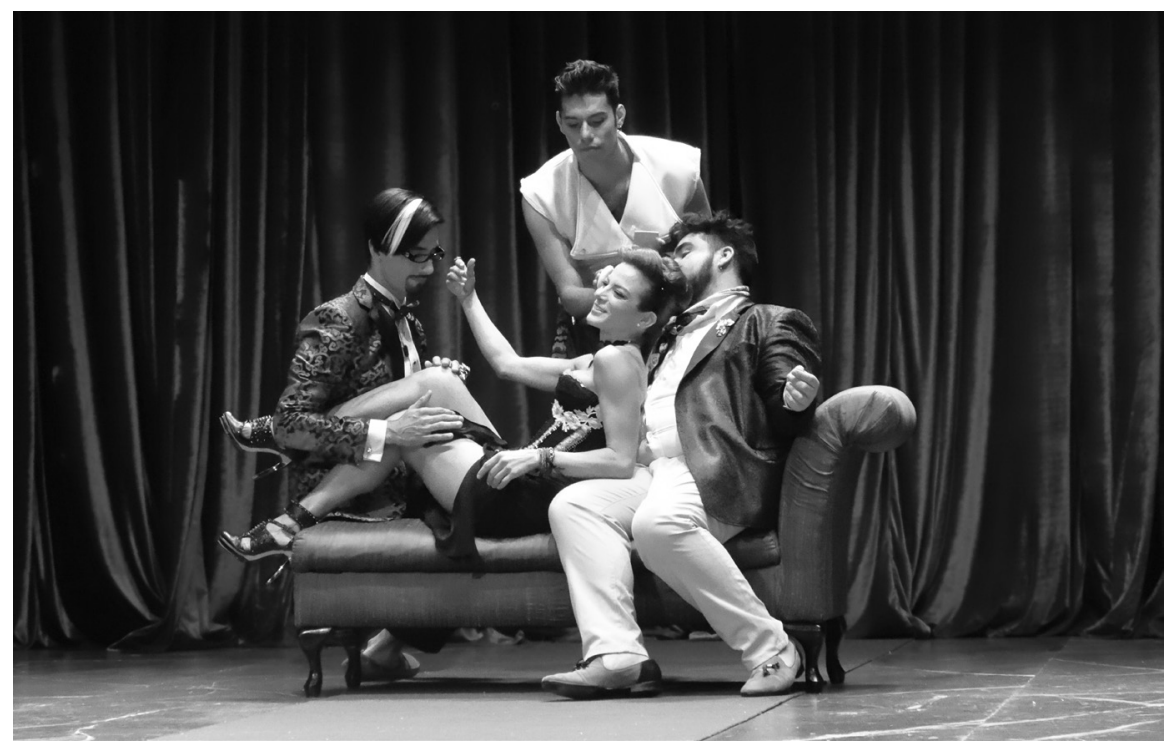

El misántropo. Fotografía: Ricardo Castillo Cuevas

A continuación intento describir tu obra teatral: Temáticamente explora la dinámica de las relaciones interpersonales en el México urbano contemporáneo, por medio de un hábil manejo del diálogo; típicamente tus personajes se agreden verbal y en ocasiones fisicamente para lograr su propósito; para el espectador, tal dinámica verbal resulta altamente humorística. ¿Estás de acuerdo con mi comentario? ¿Qué agregarías?

Estoy de acuerdo, es una percepción muy válida. Creo que el sentido del humor es una manera de ver las cosas, nunca me puedo sustraer a eso. Lo que llamas agresión tiene que ver con cierta violencia interna que los personajes tienen; algo que no está del todo explícito se manifiesta tal vez en esa fuerza. Algunos de los personajes que construyo no están muy conformes con la vida.

Para tu dramaturgia, ya descrita en la pregunta anterior, se ha acuñado el término "humor ácido", entendido en relación a la percepción del público. ¿Qué función piensas que lleva a cabo tal humor en el espectador/lector?

De darnos cuenta que somos capaces de reírnos de cosas terribles, de lo que aparentemente no te puede mover a la risa. El teatro hace reconocerte en los personajes, de ahí también viene la risa; yo puedo ser como ese personaje que está ahí, y me puedo estar riendo de algo que resulta aterrador. Con la risa el espectador también se siente a salvo del ridículo y es una forma de festejarlo al mismo tiempo. Para mí la risa es lo único verdaderamente subversivo. 
A partir del estreno de Recuerdos de bruces en el año 1992, ¿cuáles textos consideras fundamentales en tu carrera como dramaturga y por qué?

Es una pregunta difícil. Por ejemplo, Químicos para el amor ha tenido más público; la montan por aquí y por allá. Me pareció un ejercicio muy padre. A Cuestión de tres también le fue muy bien. Por otro lado, en Julio sin agosto hice un experimento en estructura que cumplió mi expectativa. Como puse en el programa de mano, "es un tiempo desacomodado en espacios y afectos". Todo partió del conflicto de la relación padre-hijo que yo quería tratar, para hablar de la masculinidad en todo su esplendor; tenía que hablar de todo, también de la homosexualidad. Pensé en cómo ponerlos a dialogar diciéndose la verdad, reclamándose. Esta confrontación es muy difícil que se dé; solo se podría dar si el padre está muerto. "Pues mátalo", me dije [risa]. Este fondo que se vuelve forma, y bajo el concepto de la masculinidad de la manera más amplia que pude, con rompimientos, este caos finalmente se vuelve entendible.

¿Qué obra/s te han dado mayor satisfacción personal, independientemente del éxito en taquilla?

Julio sin agosto, como ya mencioné. Credencial de escritor porque fue crear distintos espacios a partir de una mesa y cuatro sillas. No había utilería,

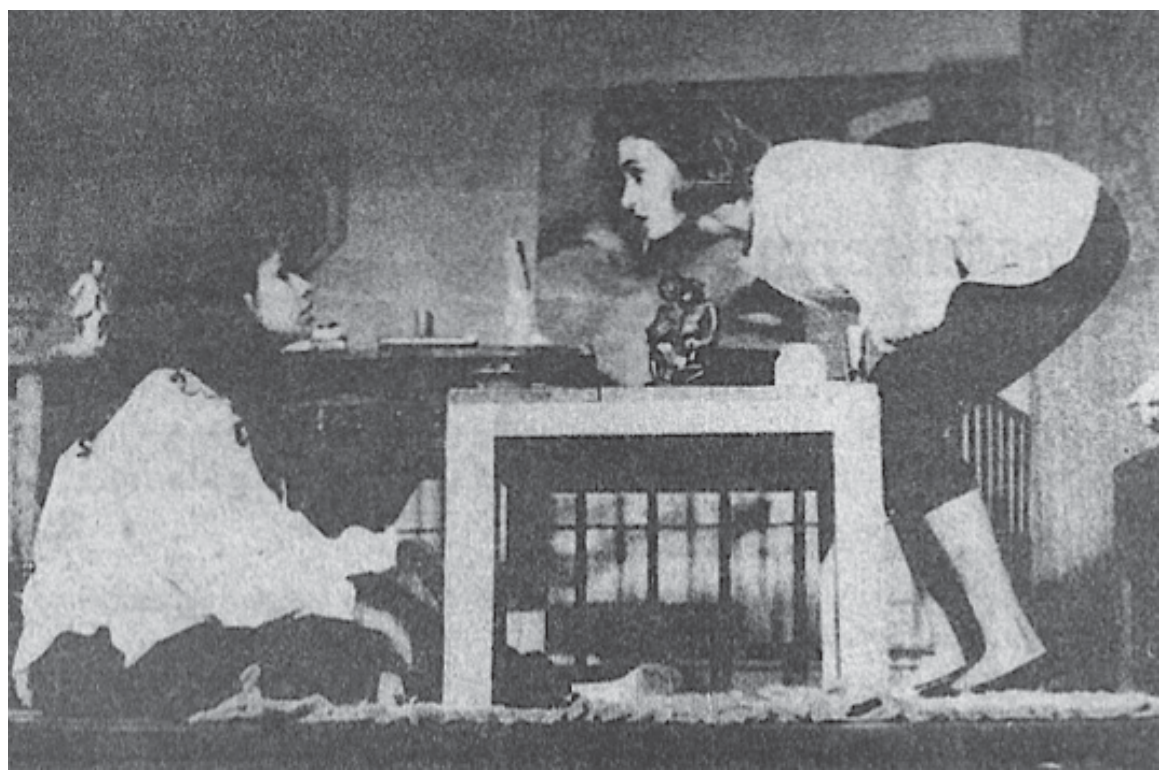

Recuerdos de bruces. Fotografía: Foro de El Museo del Carmen 
pues estorbaba por cambiar constantemente de espacio. Esta posibilidad de haber jugado con los mínimos recursos me gustó mucho. En Aplausos para Mariana me gustó llevar el final un poco al performance...

¿Se han escenificado o publicado textos tuyos en el extranjero? ¿Cuál de estas escenificaciones/ publicaciones ha sido más satisfactoria?

Se está montando Round de sombras en Chile, tiene más de un año, y está cumpliendo una función social muy importante. Presentan la obra y viene una plática después sobre la violencia de género. Nunca me planteé algo así al escribirla pero me parece valiosísimo, porque la misoginia es un problema de salud pública mundial; ya rebasó lo social. Además me dio mucho gusto haber hecho el libreto para una ópera [Loveless Scenes] que se presentó en Nueva York. Como primer acto del espectáculo estuvo Round de sombras, que es mi texto que más se ha montado; dirigí la escena de ambos. Además he tenido varias lecturas en Nueva York. Respecto a la publicación, he participado en un par de antologías de España-Argentina-México.

¿Por qué la preferencia de dirigir tus propios textos?

Porque aunque un director podría enriquecer muchísimo mis textos, termina no contando la historia que yo quiero. Prefiero hacerlo yo para contar exactamente las cosas como me las imagino.

¿Piensas que paralelamente a tu desarrollo como dramaturga has madurado como directora de escena? ¿Te interesaría dirigir obras que no son de tu autoría?

Sí, absolutamente. En el último montaje, Cuestión de tres, me sentí más segura, con más armas y más dominio de cómo llegar a donde quería; se notó en el resultado. No porque tenga la neta de la dirección; uno debe tener dudas y si no, pues estás medio frito [risa]. Sí me interesa dirigir obras de otros autores, siempre me ha interesado dirigir, pero la gente te etiqueta de que "ella solo dirige sus obras". Pues no, dirigí Estrategias contra el miedo de Ricardo García, Recordando con ira, Mexican Beauty... Lo que pasa es que para llevar a cabo esa labor titánica, una obra me tiene que gustar mucho. Por el EFITEATRO (Estímulo Fiscal al Teatro), en México se está desarrollando más la figura del productor, pero finalmente en todo lo que yo hice anteriormente de teatro tenía que ser la productora ejecutiva. ${ }^{1} \mathrm{Y}$ claro que me encantaría dirigir otras cosas. 
Respecto a la dirección, el estreno del tríptico Químicos para el amor (2002) constituye una excepción. Si bien el segmento "Manicure" lo codirigiste con José Antonio Cordero, los segmentos "Aspirinas para los desahuciados" y "Round de sombras" fueron dirigidos por Rodrigo Johnson y Sabina Berman, respectivamente. ¿Por qué esta decisión?

Los tres directores me parecen talentosos. Fue un experimento de yo llamar a los actores y a los directores y decir "a ver". A Sabina le gustaba la idea de hacerla en ese restaurante [del Teatro Helénico], esto de enterarnos de lo que está pasando en la mesa de al lado. La que hizo Rodrigo Johnson ya estaba en un restaurante. Cordero, que le tiene tirria al realismo, ahí le puso su protesta.

¿Vislumbras un futuro en que otros directores estrenen tus obras? Si cabe tal posibilidad, ¿qué director/a incluirías en tu lista?

No sé. Dependería de la obra.

En relación a la creación dramatúrgica, ¿estás trabajando en alguna obra nueva o tienes algún proyecto en mente?

Sí, estoy trabajando en una obra nueva, es un poco de terror... en la realidad no hay monstruos, los monstruos somos nosotros [risa].

\section{$2^{\mathrm{a}}$ parte. Montajes recientes}

En Julio sin agosto (2006) resulta muy efectiva la yuxtaposición temporal para indagar en las relaciones interpersonales ¿Cómo surgió la idea para este texto? ¿Consideras que marca una evolución en tu dramaturgia?

Como te decía, a partir de la relación padre-hijo, yo quería abarcar la masculinidad. Eran tres obras breves; las recorté e hice un collage y escribí las partes que faltaban para hilar la acción. También tenía que ver con la física cuántica, la cual le es propia al teatro. El tiempo no es lineal, y el objeto es determinado por quien lo mira; son dos principios fundamentales del teatro y que son más obvios en Julio sin agosto. De hecho el montaje estaba como en medio de un triángulo; lo que veían estos de acá no era lo mismo que estaban viendo estos otros. A partir de esa reflexión, se fue haciendo la obra. Creo que sí marca una evolución en mi dramaturgia; estoy orgullosa del experimento que me propuse.

Considero a Cuestión de tres un buen ejemplo de una obra atractiva tanto para un público "selecto" como para un público general, en parte por incluir 
actores conocidos en el teatro comercial y la televisión. Este equilibrio me recuerda la dramaturgia de Sabina Berman. ¿Piensas que hay una analogía entre tu teatro y el de Sabina?

Yo admiro a Sabina, pero me sería difícil decir si hay una analogía; de hecho, no creo. La naturaleza de esa producción tiene que ver más con EFITEATRO. Las empresas están haciendo con el teatro lo mismo que hicieron con el cine; una empresa, en vez de pagar a Hacienda, te da a ti dinero para que hagas una obra. Ha sido importante en el hecho que haya más producciones de ese tipo. Pero fíjate que tiene que ver particularmente con que yo admiro el trabajo de Alejandro Tommasi, me parece de los mejores actores de México, trabajó con Gurrola y Mendoza, y también en Aventurera... ha hecho de todo. Yo tenía muchas ganas de trabajar con él, y si es un actor que viene de televisión, pues no me importa $[$ risa $]$. Es interesante la taquilla pero creo que hay actores con quienes quieres trabajar, sean o no famosos. Ahí tienes a David Hevia; para mí era ideal para hacer El misántropo, y solo lo conoce la gente de teatro, pero tampoco me importó. Otro ejemplo: Silvia Navarro trabajó en la segunda temporada de Químicos para el amor, y me parece también una actriz estupenda. Si la gente va a verla al teatro, pues qué mejor. También he hecho obras sin ese afán; creo que el teatro se va a llenar si la obra es buena. Y creo que los dramaturgos mexicanos deberíamos estar en todo tipo de teatros, en los comerciales o subsidiados.

A propósito del estímulo fiscal EFITEATRO, recién vi la adaptación que hiciste de El misántropo de Molière, obra de la cual eres coproductora, y dirigida por David Olguín ¿Cómo surgió este proyecto y cuál fue tu relación con la puesta en escena? ¿Cuál fue el método a seguir para la adaptación?

El misántropo es una necedad de mi parte de hace muchos años. Yo me aboqué a ser la productora artística; reunir a la gente para llevar a cabo el proyecto. Precisamente quería romper un poco con estas etiquetas que acostumbramos ponerle a todo. Me pareció interesante llamar a gente de distintas escuelas: Silvia Navarro que es de televisión, David Hevia de teatro, Sergio Zurita que es más conocido como director y tiene un programa de radio, pero yo sabía que era buen actor, ya que estuvo en Cuestión de tres. Me gusta esto de desencasillar a la gente. David Olguín me parece muy buen director, tenía el rigor marguliano que se requiere para montar una obra de esa envergadura.

Para la adaptación, quería mantenerme lo más cercana a Molière. Lo que hice fue ser admiradora del texto, mantener este lenguaje, la musicalidad, pero bajándole tres rayitas al barroco. Mantener el barroco, con el hipérbaton 

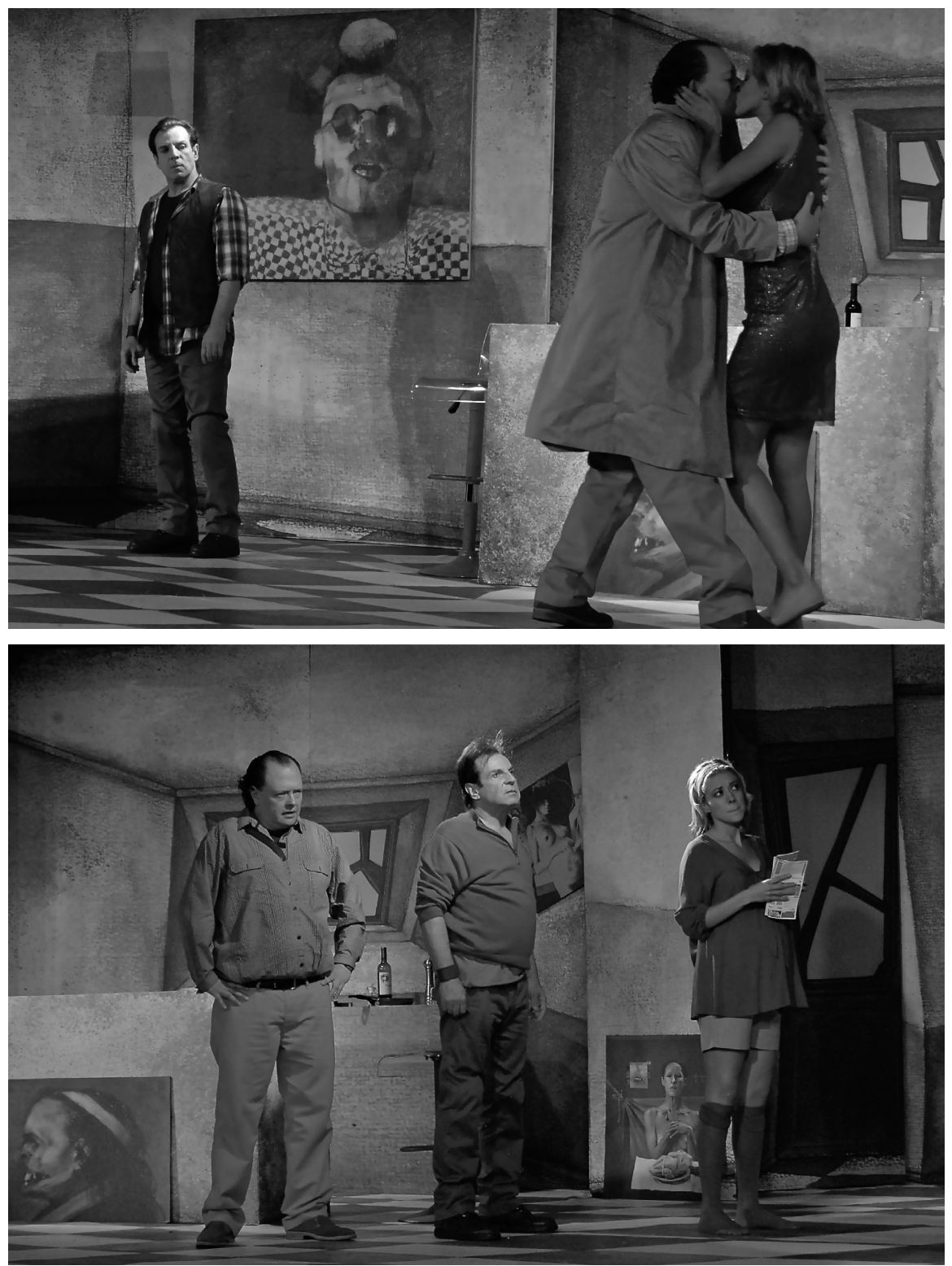

Cuestión de tres. Fotografía: Teatro Sala Chopin

y todos estos artilugios maravillosos que sirven mucho a la comedia, pero volverla más asequible para el público. Quería mantener esta belleza, este 
oropel que le es propia a la obra, porque me fascina. Edité y me volé algunas escenas, porque buscaba la síntesis, y aun así dura dos horas.

¿Piensas que existen semejanzas entre nuestra época y la de Molière, así como entre tu dramaturgia y la de este autor?

Esta obra fue muy importante para mí, como te decía. Creo que no hemos cambiado nada, y esto es un poco preocupante [risa]. Pero, en vez de preocuparme, prefiero escribir teatro y reírme. Tiene que ver con lo que te decía al principio: a estos personajes como que la vida les da urticaria; no se les da mucho el optimismo. De alguna manera el escribir teatro ya es una forma de ser positiva.

Creo que una buena adaptación es un acto de creatividad comparable al de la escritura "original" misma. ¿Qué puedes decir al respecto en base a tu experiencia? ¿Existe el proyecto de adaptar otros "clásicos" en el futuro?

No lo sé, te juro que no lo sé; cuando tú adaptas algo, tienes que estar enamorado del texto para no traicionarlo. ¿Cómo le voy a corregir la plana a Molière? Simplemente quiero guardar la esencia, para que esa hermosura se quede para un público contemporáneo, y que no se me jeteen por las tres horas del espectáculo. Por cierto, el término "versión libérrima" me da un poco de risa. "Versión" es una libertad que te tomaste; entonces "libérrima" es un tipo de pleonasmo.

Quisiera adaptar para el teatro El extranjero; me ha entrado la nostalgia de esas lecturas que me marcaron. Me parece que puede ser viable. Lo veo con posibilidades, recurriendo a la más absoluta y primaria teatralidad. Creo que será mi siguiente proyecto cuando termine la obra que estoy escribiendo.

\section{$3^{\text {a }}$ parte. Becas y otras actividades}

Tu segunda obra, Credencial de escritor (1996), fue escrita con una beca del FONCA para jóvenes creadores. En tu experiencia, ¿hasta qué grado fue decisivo en tu carrera el obtener esta beca?

Tan decisivo que yo trabajaba aquí [en La Garufa] de mesera; nos vino una crisis familiar económica y de cliente pasé a ser mesera. Pues cuando me dan la beca, me salgo; se me terminó la beca y volví de mesera. Gracias a la beca pude escribir y montar la obra.

En el prólogo al Teatro de la Gruta IX (2009) presentas los textos del ganador y finalistas del Premio Nacional de Dramaturgia Joven Gerardo Mancebo 

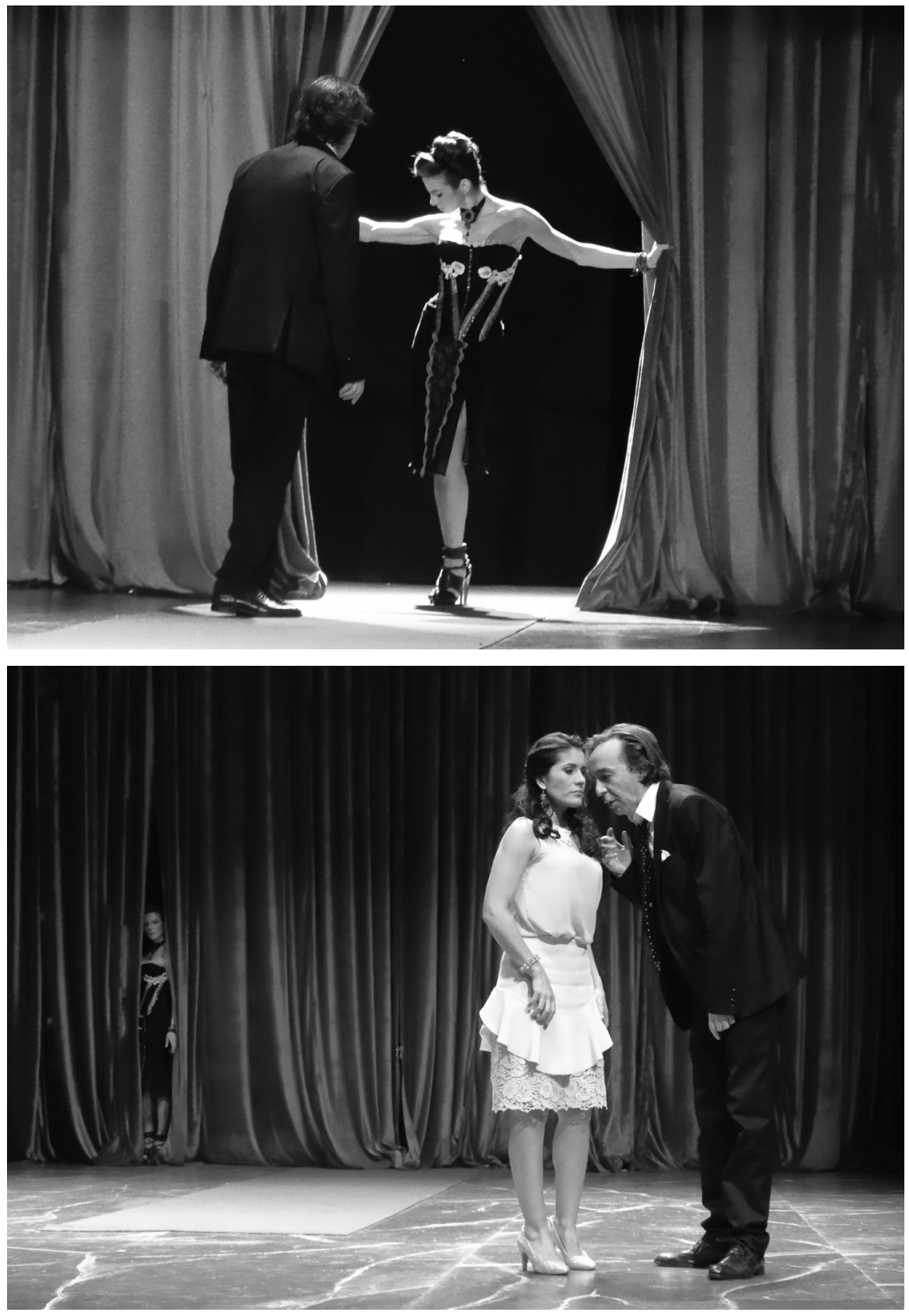

El misántropo. Fotografía: Ricardo Castillo Cuevas 
del Castillo, convocado por el FONCA y otras instituciones. Los tres galardonados (Hugo Alfredo Hinojosa, Itzel Lara y Mariana Hartasánchez Frenk) continúan su carrera como dramaturgos. ¿Piensas que estos jóvenes en su momento han tenido un mayor apoyo institucional que cuando iniciaste tu carrera? En tu opinión, ¿Cuáles han sido los aciertos del FONCA y qué cambios consideras deseables?

Sí, absolutamente. Hay muchos más apoyos. Ya es otro tiempo, me siento como ruca. Por ejemplo, para los jóvenes es más fácil estrenar en el extranjero; tienen una globalización más efectiva. El FONCA hace una labor importantísima, pero también si el creador no se mueve, no hay FONCA que valga. Estos jóvenes están porque quieren estar y trabajan para ello. Elementos que se pueden mejorar del FONCA: que me dieran la beca del Sistema Nacional de Creadores, que me ha sido negada todos estos años [risa].

También escribes narrativa, y tus cuentos se han publicado en diversas revistas. Asimismo escribes guiones para televisión. ¿Cómo complementan estos géneros tu labor creativa? ¿Qué proyectos tienes al respecto en este momento?

La narrativa influye en cuanto a mantener un misterio por la inmediatez y la sorpresa propia del cuento. Escribo televisión porque soy dramaturga; de eso vivo. Comencé a escribir televisión en Argos y en proyectos muy interesantes que querían hacer distintas las cosas. Me gusta mucho; el que es perico dondequiera es verde.

En la actualidad trabajo para Telemundo. Estoy de asesora literaria de una serie que se va a llamar Dueños del paraíso. Escribí hace poco la segunda parte de El señor de los cielos, que fue un gran éxito en Estados Unidos, y estamos empezando la tercera temporada. Tengo una novela terminada y la he enviado a dos editoriales. En cine tengo varios guiones en el cajón; espero algún día sacarlos y dirigirlos. Tengo muchas cosas que hacer.

Además de la escritura (en cualquiera de sus modalidades) y la dirección escénica ¿Qué otras actividades realizas en este momento / planeas incursionar en el futuro?

Quisiera tener tiempo para leer más; me gustaría llevar al cine Cuestión de tres. Unas amigas de cine me entusiasmaron. Es una labor titánica, pero hay que empezar. No quiero quedarme con las ganas de hacer lo que quiero hacer.

Muchas gracias por la entrevista.

Hampden-Sydney College 


\section{Notas}

1 Todas las fechas corresponden al estreno. La obra Químicos para el amor se escenificó en la cafetería del Teatro Helénico y consta de tres segmentos: "Aspirinas para los desahuciados", "Round de sombras" (estrenado previamente en 1996) y "Manicure".

2 EFITEATRO: "estímulo fiscal para los contribuyentes del impuesto sobre la renta que otorga el Artículo 226 Bis de la Ley del Impuesto sobre la Renta (LISR), con el fin de apoyar a los Proyectos de Inversión en la Producción Teatral Nacional". <http://www.conaculta.gob.mx/financiamiento_efiteatro/\#.UwUkIBdVIU, consultado el 13 de agosto, 2014>. 